\title{
Resenha
}

\section{O ser interior na psicanálise: fundamentos, modelos e processos ${ }^{1}$}

\author{
Cristina Maria Filomena Monzoni PRESTES²
}

O autor convida o leitor a refletir sobre a psicanálise e o modo de praticá-la. Sugere uma atitude mental que conduz a novas aberturas para a compreensão das perturbações psíquicas, e também da evolução mental.

A psicanálise é considerada uma ciência que provê insight do mundo mental no todo. É uma tentativa de compreensão baseada na inter-relação de alguns fatores, considerados no aspecto macroscópico, por meio da observação e caracterização da existência do sistema mental dominante. Apresenta uma organização metodológica de dados, mais do que uma reestruturação de conceitos psicanalíticos clássicos, de modo que, a partir desta perspectiva, os principais autores em psicanálise (Freud, Klein, Bion e Winnicott) conseguem dialogar entre si. Introduz a noção de ser interior e de como esse ser se compõe com o conjunto dos demais fatores, aspectos e elementos presentes na personalidade. O modelo proposto está relacionado ao eixo do contínuo de contato, que, como estrutura baseada no contato com o ser interior, mostra-se como uma linha de base que norteia a sistematização de fenômenos psíquicos.

O ser interior corresponde aquilo que a pessoa intrinsecamente é desde o começo de sua vida. É uma matriz da existência que define a situação fundamental na qual é constituída a condição de pessoa. Cada pessoa tem seu ser profundo, singular e específico, revelando- -se como vida; é estável em sua matriz existencial. Pode-se expandir somente em conformidade com o que intrinsecamente é. É um núcleo de existência, um foco de relações, ligações, experiências e vínculos profundos; é não sensorial na sua constituição. Há diferentes formas de manifestação do ser interior nas pessoas, dependendo do tipo de contato estabelecido com ele.

O tipo de contato é variável de pessoa para pessoa, e também pode se alterar durante a vida de uma mesma pessoa. As noções sobre si mesmo dependem desta variação.

As noções que uma pessoa tem a respeito de seu ser estão sujeitas à especificidade do contato e ao quanto ele é profundo, abrangente e sólido, ou superficial, estreito e inconstante.

Os diversos graus de contato determinam a noção do ser para si mesmo, bem como o tipo de influência que ele exerce em sua vida. A forma como este contato se manifesta também é variável, podendo ser visível (indireto, fragmentário ou dispersivo) ou submerso e invisível. O contato pode se realizar de modo inconsciente, consciente e oclusivo.

A noção de ser interior não se confunde com a noção de self. O ser interior é um foco da existência, e o selfé um órgão mental de execução dessa existência, um meio pela qual ela se efetiva. A relação entre ambos é estreita. O ser interior influencia o selfe, dependendo

1 Trinca, W. (2007). O ser interior na psicanálise: fundamentos, modelos e processos. São Paulo: Vitor Editora.

2 Curso de Introdução à Psicoterapia Psicanalítica. R. Dra. Maria Augusta Saraiva, 67, VI. Olímpia, 04545-060, São Paulo, SP, Brasil. 
do tipo de influência, determinará a natureza e a qualidade dos processos que nele ocorrem. Uma maior ou menor influência implicará diferentes modalidades de self.

Como órgão de contato, o self tem capacidade de se conectar em maior ou menor grau com o ser interior. Estruturalmente, não é o ser interior que forma o self, pois, como componentes psíquicos, são distintos entre si. Dinamicamente, porém, dependendo da maior ou menor influência do ser interior sobre o self, este se estrutura em maior ou menor conformidade com a verdade existencial da pessoa, com aquilo que ela essencialmente é. Atividades de processos psíquicos fundamentais de sustentabilidade são realizadas. Sob a influência do ser interior, o self torna-se o fator fundamental para a organização da personalidade e uma instância compatível com a verdade interna. Mas, se a influência do ser interior sobre o selffor insuficiente ou precária, ele se torna um campo minado pela fragilidade, ou um refúgio para a sensorialidade.

O self organiza-se sob a influência do ser interior e modifica-se com a distância do contato. Na medida em que existem diferentes graus de distanciamento, em cada um são relatadas formações especiais de fragilidade e sensorialidade no self.

O distanciamento do contato é um fator determinante que, junto a outros fatores, é responsável por turbulências e desordens psíquicas. Assim, quanto maior o contato com o ser interior, maior é o grau de harmonização e integração psíquica e, inversamente, quanto maior a distância, há aumento no nível de turbulência emocional, surgindo fragilidade e sensorialidade no self.

Essas ideias podem ser colocadas em um eixo do contínuo de contato que, como estrutura básica, serve de suporte ao modelo apresentado, destinado à organização e à compreensão das perturbações psíquicas. Assim, hipoteticamente, é possível determinar, em cada ponto do eixo uma organização particular, a dinâmica específica, as qualidades e as condições internas do self, permitindo, deste modo, a sistematização de uma vasta gama de fenômenos, como os sistemas mentais determinantes e a experiência de imaterialidade. O eixo é constituído por um campo de variação contínua entre infinito negativo e infinito positivo, prestando-se a ser uma referência agregadora de formas variadas de atividade mental.
Este modelo também serve de sustentação para outros desdobramentos, que são colocados sob o critério do contato com o ser interior. São os graus de contato que vão determinar, em relação ao eixo, quais os fenômenos psíquicos que aparecem e que necessitam ser considerados. Isto é, o contato é uma noção variável que abrange os estados oclusivo, inconsciente e consciente, constituindo um eixo de variação contínua que se mostra por fenômenos diferenciados em cada ponto.

Uma das razões do distanciamento de contato é a constelação do inimigo interno, que se opõe totalmente à natureza da vida mental. É constituído de elementos cuja ação tem como denominador comum o ataque e a destruição do contato com o ser interior, e cujos objetivos são desequilibrar, suprimir e aniquilar a individualidade, bem como os laços com a vida e o viver.

A observação clínica leva à descrição de diferentes estágios da constelação do inimigo interno, estruturados na natureza, no tipo de ataque e na sua intensidade. Caracterizam-se como dúvidas e descréditos, autodepreciações e autoinvalidações. Quanto mais elevados forem os graus de distanciamento de contato, mais elevados serão, de forma correspondente, os graus de fragilidade do self e, por conseguinte, de esvaziamento do self.

O estágio em que estiver o paciente em relação à constelação do inimigo interno constitui por si só um indicador importante para o conhecimento de grande número de perturbações psíquicas, porque ajuda a revelar o grau de distanciamento do contato. Segundo o modelo do eixo de um contínuo de contato, devem-se ter em mente, se possível, os graus de distanciamento de contato em função desses estágios e em combinação com as influências relativas dos demais fatores, porque, deste modo, passa-se a ter informações sobre os tipos e as intensidades das escolhas patológicas, entre outros aspectos.

Muitos outros elementos contribuem para o distanciamento de contato e para o afastamento da influência do ser interior sobre o self. Uma pessoa pode se dispersar, se confundir ou se perder de si por inúmeras razões: a incrementação de angústias por ameaças reais do mundo externo, a debilitação do self por conta de relações objetais difíceis, os problemas superegoicos, as facilidades de se envolver e de se misturar em pro- 
cessos que Ihe são estranhos, a falta de condições suficientes para se interiorizar, a supressão e a evasão de emoções etc. Entretanto, os principais fundamentos do modelo continuam inalterados, pois o distanciamento de contato é seguramente um dado primário no estudo das perturbações psíquicas.

O afastamento de presença e de atuação do ser interior, seus efeitos e desdobramentos levam a graus diversos de perturbações psíquicas. A cada ponto da variável 'distanciamento de contato' correspondem diferentes processos psíquicos e, portanto, diferentes naturezas de perturbações psíquicas. Uma descrição das perturbações psíquicas pode ser feita por meio das condições do self, perante as forças em movimento que assumem o lugar do ser interior. Assim, as perturbações psíquicas, para se instalarem, dependem do comportamento do self em face do distanciamento de contato. Como estas condições ocorrem no self, e como este se sujeita às leis do distanciamento de contato, para estudá-las é necessário estabelecer correspondência entre esse distanciamento e o que ocorre no self, considerando que, geralmente, os processos conflituosos originados das relações objetais, do superego e de outras partes da mente refletem-se sobre o self, onde se localizam os conflitos e as turbulências. Deste modo, o selfé tomado em graus por forças que operam fora de sintonia ou em oposição ao ser profundo.

Em decorrência do distanciamento de contato, há um processo de fragilização do self. Mecanismos psíquicos amplamente conhecidos em psicanálise, como cisão, identificação projetiva e fragmentação, são verdadeiros arranques deste processo. A fragilidade do self dá-se em graus e pode ser observada clinicamente. Encontram-se graus de diminuição do fortalecimento, graus de enfraquecimento e graus de esvaziamento do self.

No eixo de contínuo de contato organizam-se os sistemas mentais determinantes, formados por quatro fatores: a constelação do inimigo interno, o distanciamento de contato, a sensorialidade e a fragilidade do self. Cada sistema mental determinante é tomado como unidade indissolúvel, definido pela presença, posição e grau dos fatores que o compõem. Para conhecer a natureza do sistema mental dominante, necessita-se saber, por meio da observação clínica, qual a modalidade de orientação da pessoa entre a sensorialidade e a fragilidade do self, bem como qual é o tipo de sensorialidade ou a espécie de fragilidade presente. Assim, cada uma dessas variações compreende um lugar de desordens psíquicas, que vão desde as mais simples até as mais severas e complexas formas de doença mental.

O modelo apresentado amplia os estudos psicanalíticos. Introduz a noção do ser interior como núcleo essencial, diferenciado do self, e as consequências das relações entre ambos para a compreensão das desordens psíquicas. Demonstra que o grau de contato com o ser interior pode levar à saúde ou à doença mental.

O livro gera a expectativa de outros trabalhos que ofereçam mais reflexões sobre este modelo. Livros como O Ser Interior na Psicanálise estimulam o desenvolvimento da ciência psicanalítica.

Recebido em: 26/11/2008

Aprovado em: 9/2/2009 
